\title{
Compression Precracking Methods to Generate Near-Threshold Fatigue-Crack-Growth-Rate Data
}

\author{
J. C. Newman, $\mathrm{Jr}^{1, a}$ and Y. Yamada ${ }^{1, b}$ \\ ${ }^{1}$ Department of Aerospace Engineering, Mississippi State University, Mississippi State, MS, USA \\ aj.c.newman.jr@ae.msstate.edu, byy67@msstate.edu
}

Keywords: Cracks, fatigue-crack growth, load reduction, compression, compact, stress-intensity factor, crack closure, plasticity, roughness, fretting debris.

\begin{abstract}
Some of the fatigue-crack-growth-rate data generated in the threshold and near-threshold regimes on two aluminum alloys (7075-T651, 7075-T7351), a titanium alloy (Ti-6Al-4V $\beta$-STOA), a high-strength 4340 steel and a nickel-based superalloy (Inconel-718) were determined by using the compression precracking constant-amplitude (CPCA) and compression precracking loadreduction (CPLR) test methods. Tests were conducted over a range in stress ratios $(\mathrm{R}=0.1,0.4$ and $0.7)$ on compact specimens. Results are compared with threshold and near-threshold data generated on the same materials using the ASTM E-647 load-reduction test procedures. One of the aluminum alloys (T651) and the 4340 steel showed very little difference between the methods; however, the other materials showed significant differences with the compression precracking test methods giving lower thresholds and faster crack-growth rates than the ASTM load-reduction method.
\end{abstract}

\section{Introduction}

Accurate representation of fatigue-crack-growth thresholds is extremely important for many structural applications. In the United States, the threshold regime is experimentally defined by using a load-reduction test procedure [1]. In the early 1970's, a load-reduction test method was developed by Paris et al $[2,3]$ to generate data at low stress-intensity-factor ranges and approaching threshold conditions. Later, Hudak et al [4] finalized the method, which was incorporated into ASTM E-647 fatigue-crack-growth-rate testing standard. During the same time, Ohta et al [5] and Minakawa and McEvily [6] showed a rise in the crack-closure levels as the threshold conditions were approached using load-reduction methods. This behavior was attributed to roughness- and fretting-debris-induced crack-closure effects. The load-reduction test methods had also been shown to exhibit anomalies due to load-history effects from residual-plastic deformations $[7,8]$. The current load-reduction test method may produce data, which exhibit "fanning" in the threshold regime with stress ratio. It is suspected that the load-reduction test method induces remote closure, which prematurely slows down crack growth, and produces abnormally high thresholds for low stress-ratio conditions. The fanning could also be caused by environment, which naturally produces oxide and/or fretting-debris and higher closure levels $[9,10]$. It has also been suspected that cracksurface roughness is more prevalent in the threshold regime, which could also cause higher closure levels at low stress-ratio conditions [10,11]. To generate fatigue-crack-growth-rate data in the threshold and near-threshold regimes, without appreciable load-history effects, a "compressioncompression" precracking method, developed by Hubbard [12], Topper and Au [13], Pippan et al [14,15], Forth et al [16] and Newman et al [17] is used. Environmental effects, such as oxide and/or fretting-debris-induced closure, crack-surface roughness-induced closure, and plasticity-induced closure would naturally develop under "constant-amplitude" loading conditions.

This paper will present some of the fatigue-crack-growth-rate data in the threshold and nearthreshold regimes on a wide variety of materials, using a compression-compression precracking constant-amplitude (CPCA) and/or a compression-compression precracking load-reduction (CPLR) test method. Using the CPCA or CPLR test methods, notched compact specimens were cycled 
under compression-compression loading (sufficient to yield the crack-starter notch tip) to produce an initial crack, which naturally stops growing. Then the specimen was subjected to constantamplitude loading to generate crack growth in the near threshold regime at the desired stress ratio. It had been estimated that crack growth of about 3 compressive plastic-zone sizes from the crackstarter notch was required to generate "steady-state" results under low stress-ratio conditions. Later, elastic-plastic finite-element simulations of the CPCA test method verified the crackextension criterion beyond which crack growth is not affected by the crack-starter notch, the tensile residual stresses caused by compressive yielding, and the stabilization of plasticity-induced crack closure [18]. The utility of the CPLR test method is to grow the crack under CA loading until the crack-extension criterion has been met and then conduct a standard LR test, but the initial starting stress-intensity factor conditions are very low compared to the traditional LR method.

Fatigue-crack-growth-rate data has been generated in the threshold and near-threshold regimes on two aluminum alloys (7075-T651, 7075-T7351), a titanium alloy (Ti-6Al-4V $\beta$-STOA), 4340 steel and Inconel-718 using compression precracking constant-amplitude (CPCA) and compression precracking load-reduction (CPLR) test methods. Tests were conducted over a wide range in stress ratios $(\mathrm{R}=0.1,0.4$ and 0.7$)$ on compact specimens, but only some results are presented herein. The results determined using the compression precracking methods are also compared with data generated on the same materials using the ASTM E-647 load-reduction test procedures.

\section{Background}

A schematic of the expected behavior for load-reduction and CPCA loading is shown in Fig. 1. The objective is to determine "steady-state" constant-amplitude results (solid curve) at a constant stress (R) ratio, without any load-history effects. The traditional load-reduction scheme has been shown to induce higher thresholds than steady-state conditions [16,17]. Also, the thresholds have been shown to be influenced by the initial $\Delta \mathrm{K}$ level at which the load-reduction procedure was applied [19]. A load-reduction test starts at an initial $\Delta \mathrm{K}_{\mathrm{i}}$ level, such as $\Delta \mathrm{K}_{2}$, and the maximum and minimum loads are reduced as the crack grows to slowly reduce $\Delta \mathrm{K}$, and to maintain constant $\mathrm{R}$. If a lower $\Delta \mathrm{K}$ value is used, such as $\Delta \mathrm{K}_{1}$, a lower threshold may be generated. After the threshold is reached, an increasing load test is generally conducted to obtain the upper region of the $\Delta \mathrm{K}$-rate curve.

On the other hand, a crack grown under the CPCA loading is fully open at the start of constantamplitude loading (constant $\Delta \mathrm{P}_{\mathrm{i}}$ at a given $\mathrm{R}$ ) after compression precracking. During constantamplitude loading, the crack may rapidly slow down and approach the steady-state curve from above. The crack, which is initially fully open, is growing because of the tensile residual stresses induced by the compressive yielding at the crack-starter notch and the constant-amplitude load range is fully effective (no crack closure). Currently, trial-and-error procedures are required to select the initial tensile loading $\Delta \mathrm{P}_{\mathrm{i}}$ (constant $\mathrm{R}$ ) to start the test at the unknown threshold value. If a tensile load range is selected that would produce a stress-intensity factor range below the threshold, such as $\Delta \mathrm{P}_{1}$, then the crack may initially grow but become a non-propagating crack; however, if the load is high enough, then the crack will grow. At low initial values, such as $\Delta \mathrm{P}_{2}$, an over shoot (rates below the steady-state condition) may occur in the results based on FASTRAN [20] simulations. At higher load amplitudes, such as $\Delta \mathrm{P}_{3}$, the crack will continue to grow. It is estimated that the crack must be grown several compressive plastic-zone sizes before the effects of the tensile residual stresses (due to compressive yielding at the notch) has decayed and that the crack-opening stresses have stabilized under steady-state conditions. The $\Delta \mathrm{K}_{\text {eff }}$ curve (dash-dot curve) is the $\Delta \mathrm{K}$-rate curve for high stress ratios and is the characteristic behavior of a fully open crack. The $\Delta \mathrm{K}_{\text {eff }}$ curve may or may not be parallel to the steady-state curve due to threedimensional constraint and environmental effects. 


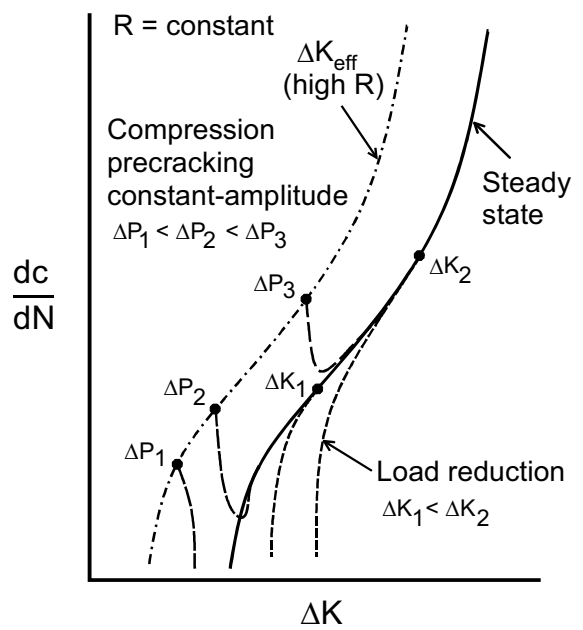

Fig. 1 - Typical fatigue-crack-growth data under constant-amplitude, load-reduction and CPCA loading.

\section{Materials and Specimen Configuration}

A wide variety of materials were tested to determine the threshold and near-threshold fatigue-crackgrowth-rate behavior using several testing methods. The materials, thickness and tensile properties are given in Table 1. The 7075-T651 material was obtained from Northrop Grumman and was machined from a 50-mm thick plate, near the free surface, to simulate the outer wing skin for an aircraft wing; the 7075-T7351 plate and Ti-6Al-4V $\beta$-STOA (forging block) was obtained from Sikorsky; the 4340 steel and Inconel-718 specimens were obtained from Boeing.

Table 1. Material thickness and tensile properties.

\begin{tabular}{|l|c|c|c|}
\hline \multicolumn{1}{|c|}{ Material } & $\begin{array}{c}\text { Thickness, } \\
\mathrm{B}[\mathrm{mm}]\end{array}$ & $\begin{array}{c}\text { Yield stress, } \\
\sigma_{\mathrm{ys}}[\mathrm{MPa}]\end{array}$ & $\begin{array}{c}\text { Tensile strength, } \\
\sigma_{\mathrm{u}}[\mathrm{MPa}]\end{array}$ \\
\hline 7075-T651 & 5.7 & 545 & 586 \\
\hline 7075-T7351 & 9.8 to 11.2 & 415 & 490 \\
\hline Ti-6Al-4V $\beta$-STOA & 9.5 & 895 & 965 \\
\hline 4340 Steel & 6.35 & 1240 & 1310 \\
\hline Inconel-718 & 9.5 & 1060 & 1350 \\
\hline
\end{tabular}

All test specimens were standard plan-form compact $\mathrm{C}(\mathrm{T})$ specimens either 50.8 or $76.2-\mathrm{mm}$ wide $(\mathrm{W})$. The initial crack-starter notch length, $\mathrm{c}_{\mathrm{n}}$, was about $35 \%$ of the width. An automated data acquisition system with a back-face strain-gage mounted on the $\mathrm{C}(\mathrm{T})$ specimens were used to monitor the crack lengths during the tests.

\section{Test Procedures}

All tests were performed under laboratory air conditions in $25 \mathrm{kN}$ (5.6 kip) servo-hydraulic test machines. Crack lengths were monitored using back-face strain-gage compliance procedures, as outlined in E-647 [1]. Test control was provided by a data acquisition/test control system for 
threshold fatigue-crack-growth-rate testing. Crack growth rate testing was performed at stress ratios, $\mathrm{R}$, ranging from 0.1 to 0.7 , at a nominal cyclic frequency of $18 \mathrm{~Hz}$.

Threshold and near-threshold testing was performed using three methods. The first method was the standard load-reduction (LR) method described in E-647 for threshold determination. Initial starting load levels were carefully selected to ensure that growth rates immediately from the starting notch were less than $10^{-8} \mathrm{~m} /$ cycle $\left(4 \mathrm{e}^{-7}\right.$ in/cycle), as required in the standard. A load reduction rate of $\mathrm{C}=-0.08 \mathrm{~mm}^{-1}\left(-2 \mathrm{in}^{-1}\right)$ was maintained in all LR tests. Upon developing rates at or near the target $10^{-10} \mathrm{~m} /$ cycle, test control was changed to constant amplitude (CA) loading at higher $\Delta \mathrm{K}$ values to generate the mid- and upper regions of the crack-growth rate curve.

The second method was compression precracking, followed by CA loading, and referred to as CPCA. Fig. 2(a) shows how the specimens were precracked under compression-compression loading. Small metallic blocks were bonded to the top and bottom edges of the specimen, such that the loading clevises would contact and transmit cyclic loads $(5-10 \mathrm{~Hz})$ to the specimen. Smaller pins (loose) were used as a safety issue to prevent the specimens from accidentally coming out of the clevis. The stress-intensity factor solution for the compressive-loaded case is within $\pm 0.5 \%$ of the standard stress-intensity factor solution $(0.2<\mathrm{c} / \mathrm{W}<0.8)$ for the compact specimen [17].

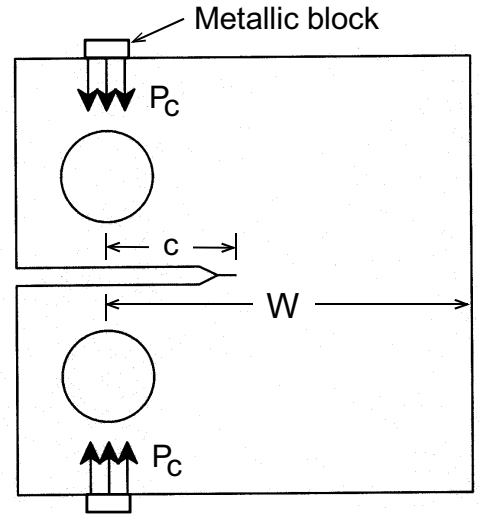

(a) Compression loading

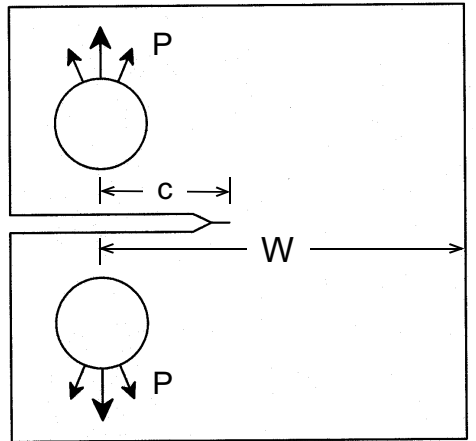

(b) Standard pin loading

Fig. 2 - Method of loading applied to compact specimens.

In this method, a small fatigue crack, which naturally stops growing, is produced at the tip of the crack-starter notch via compression-compression load cycling. A small tensile residual-stress field instead of the typical compressive residual stresses from tension-tension loading envelops the resulting crack tip. In general, when the crack stops growing, the crack surfaces are fully open. Typical crack lengths from the notch tip were $0.4 \mathrm{~mm}( \pm 0.2 \mathrm{~mm})$ resulting from compression cycling at $\mathrm{R}=10$ to 40 . Compressive load levels required to produce fatigue cracks within $100 \mathrm{~K}$ cycles were estimated from the following relationship:

$$
\mathrm{K}_{\mathrm{cp}} / \mathrm{E}=0.00032 \sqrt{\mathrm{m}} .
$$

where $\mathrm{K}_{\mathrm{cp}}$ is the maximum compressive stress-intensity factor during compression precracking and $\mathrm{E}$ is the elastic modulus. Following compression precracking, constant amplitude (CA) loading was performed at or below the anticipated threshold stress-intensity factor range until steadily increasing growth rates occurred. If no appreciable crack growth occurred after approximately 1 million cycles, then loads were increased $\sim 5-10 \%$ (maintaining constant $\mathrm{R}$ ) and, again, cycled to 
examine for crack growth. Once the crack begins to slowly grow, loads were held constant. This procedure is depicted in Fig. 3(a).

Once crack growth was detected, the fatigue crack was extended 2 to 3 compressive plastic-zone sizes (based on the compressive precracking conditions) from the initial notch tip prior to taking any valid crack-growth-rate data to eliminate potential transient effects resulting from the compressive loading and resulting tensile residual stresses. Based on extensive testing and analyses [16-18,21], an expression to determine the required crack extension beyond which the crackgrowth-rate data would not be affected by compressive yielding at the V-notch and produce "steady-state" constant-amplitude data (stabilized crack-opening stresses) in the near threshold regime is

$$
\Delta \mathrm{c} \geq 3(1-\mathrm{R}) \rho_{\mathrm{c}}
$$

where $\rho_{c}$ is the compressive plastic-zone size calculated from the plane-stress equation by

$$
\rho_{\mathrm{c}}=(\pi / 8)\left(\left|\mathrm{K}_{\mathrm{cp}}\right| / \sigma_{\mathrm{o}}\right)^{2}
$$

$\mathrm{K}_{\mathrm{cp}}$ is the compressive stress-intensity factor and $\sigma_{\mathrm{o}}$ is the flow stress of the material (average between the yield stress and ultimate tensile strength).

The third method was compression precracking, followed by CA loading, and then load reduction (LR) following E-647 procedures, except that the initial stress-intensity factor range and crack-growth rate at the start of LR test is much less than the current standard. This method is referred to as CPLR. It is suspected that the maximum allowed rate in the ASTM LR standard $\left(10^{-8}\right.$ $\mathrm{m} /$ cycle) is too high for some materials and produces elevated thresholds and slower growth rates.

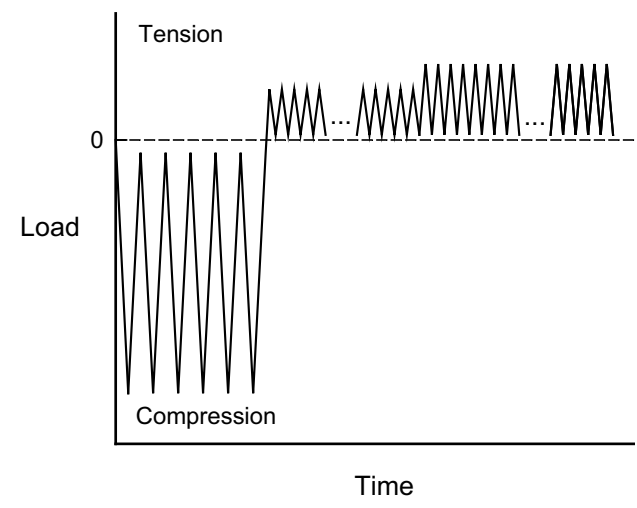

(a) CPCA loading

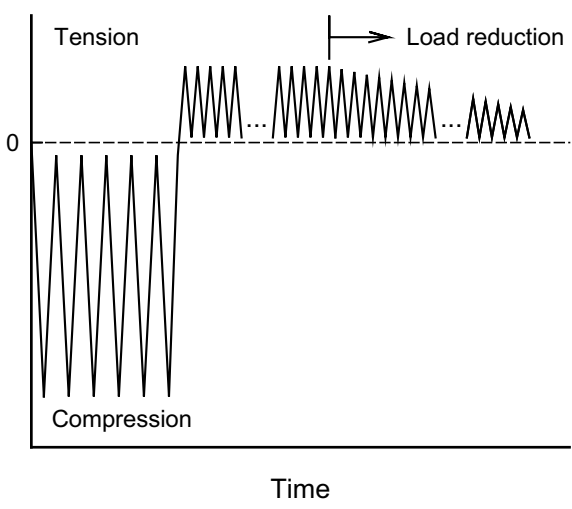

(b) CPLR loading

Fig. 3 - Types of loading applied to compact specimens.

\section{Experimental Results}

Aluminum Alloy 7075-T651. Four tests have been conducted on $\mathrm{C}(\mathrm{T})$ specimens at $\mathrm{R}=0.1$ and these results are shown in Fig. 4. Three specimens were tested using the new CPCA test method, while one specimen used the traditional ASTM LR test method. After compression precracking (CP), Test 1 had an initial $\Delta \mathrm{K}$ (at constant loads) slightly higher than the estimated threshold. From the crack-length-against-cycles data, the secant method was used to calculate $\Delta \mathrm{K}$ against rate data. 
The initial data was affected by the tensile residual stresses, but the diamond symbol at the highest $\Delta \mathrm{K}$ value shows where the crack-extension criterion is met for Test 1 . For higher $\Delta \mathrm{K}$-rate data, the results are considered valid. A second test was then conducted at a slightly lower initial $\Delta \mathrm{K}$ value and the data agreed with the first test results after the crack-extension criterion was met. But a third test had an initial $\Delta \mathrm{K}$ value much lower than the estimated threshold. Under the initial CA loading, the crack-growth rates rapidly dropped down to almost $10^{-11} \mathrm{~m} /$ cycle. The maximum load was then increased by $10 \%$ and the rates again rapidly dropped. The maximum load was again increased by $5 \%$ and the rates were now sporadic indicating that the crack was close to a threshold condition. The last load increase of $5 \%$ caused the rates to slowly increase. The lowest diamond symbol shows the crack-extension criterion for Test 3. From start to finish, Test 3 consumed 15 million cycles.

The open symbols show results of a single LR test that fell at slightly lower rates than the CPCA test results and would have produced a slightly higher threshold. But the differences are not considered significant and, thus, these results are essentially in agreement. Further tests at $\mathrm{R}=0.1$ and 0.7 (not shown) also showed good agreement between the two test methods [21]. However, the CPCA test method required a factor-of-3 more cycles to achieve the same results. The CPLR test method was not used on this material, but would have took far less cycles than the CPCA method, very much like the LR test. For example, Test 1 or 2 could have been used to conduct a LR test after the crack-extension criterion was met. In all tests, the crack surfaces were fairly flat and the cracks grew very straight.

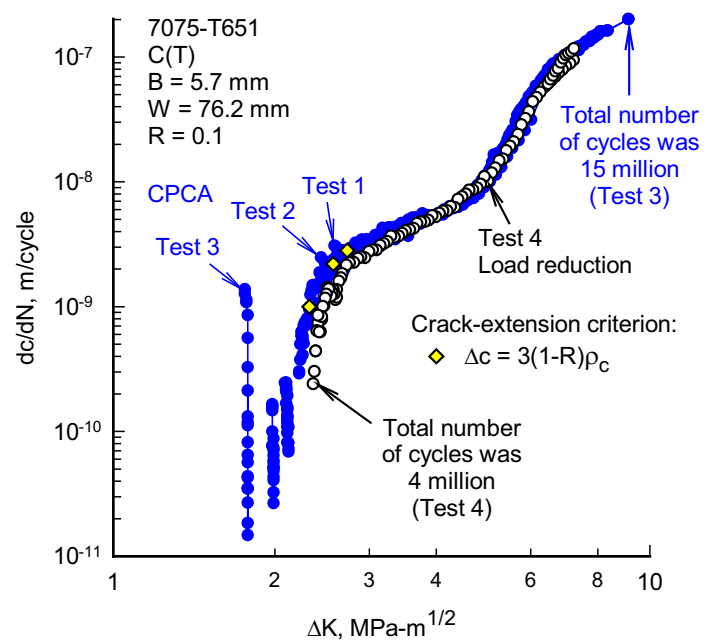

Fig. 4 - Crack-growth rate data on 7075-T651 aluminum alloy at $\mathrm{R}=0.1$.

Aluminum Alloy 7075-T7351. Fig. 5 shows fatigue-crack-growth rates against $\Delta \mathrm{K}$ for the 7075 $\mathrm{T} 7351$ alloy at $\mathrm{R}=0.1$ and 0.7 , in addition to, a constant $\mathrm{K}_{\max }$ test (triangular symbols). The open symbols show the load-reduction and load-increasing (LRI) tests conducted by Forman [22]. These results show "fanning" with the stress ratio, in that, the spread in data with $\Delta \mathrm{K}$ at low rates were greater than those in the mid- and higher-rate regions. The constant $\mathrm{K}_{\max }$ and $\mathrm{R}=0.7 \mathrm{LRI}$ test results are shown for reference, since high- $\mathrm{R}$ or $\mathrm{K}_{\max }$ test results are considered to be closure free.

The CPCA test results at $\mathrm{R}=0.1$ are shown by the solid curves. After CP loading, four tests were conducted. Each test had progressively lower initial $\Delta \mathrm{K}$ values and showed an initial high rate, which agreed fairly well with the $\mathrm{K}_{\max }$ or $\mathrm{R}=0.7$ test results. Recall that after CP loading, the 
crack surfaces are fully open and the test results should then agree with the non-closure curves. For the $\mathrm{R}=0.1$ case, large differences were observed between CPCA and LR results in the threshold and mid-rate regimes. Three CPCA test results overlapped each other before merging with the LRI results at about $1 \mathrm{E}-08 \mathrm{~m} /$ cycle. The CPCA test with the lowest $\Delta \mathrm{P}$ had an inadvertent overload at about the $3(1-\mathrm{R}) \rho_{\mathrm{c}}$ criterion (large diamond symbol). Another test at the same low $\Delta \mathrm{P}$ was grown until the test overlapped the other CPCA tests. These results demonstrated that a load-history effect must have influenced the load-reduction test results in the threshold and mid-rate regimes. In contrast to the T651 alloy, the T7351 crack surfaces were fairly rough, but the cracks tended to grow fairly straight.

Further CPCA and LR test results at $\mathrm{R}=0.4$ (not shown) also showed significant differences between the two test methods in the threshold and near-threshold regimes [17], like the $\mathrm{R}=0.1$ test results. The $\mathrm{R}=0.7 \mathrm{CPCA}$ test results (not shown) fell in between the constant $\mathrm{K}_{\max }$ and the $\mathrm{R}=$ 0.7 LRI results, but agreed extremely well with the LRI test results at higher rates.

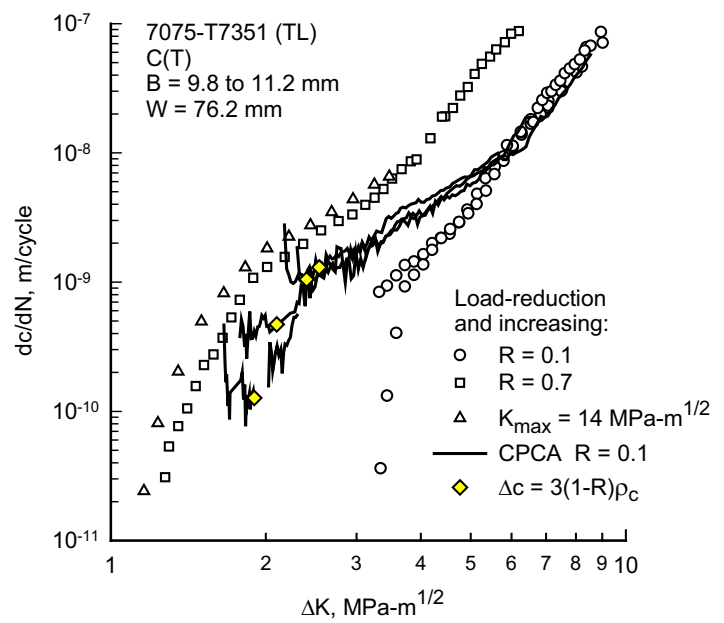

Fig. 5 - Crack-growth rate data on 7075-T7351 aluminum alloy at $\mathrm{R}=0.1$.

Titanium Alloy Ti-6Al-4V $\beta$-STOA. Testing on the titanium alloy was made on $\mathrm{C}(\mathrm{T})$ specimens machined from a forging in the SL-orientation. Tests were conducted with CPCA loading, CPLR loading and the ASTM load-reduction (LR) method. The latter tests were designed to use the maximum allowed rate in the ASTM E-647 standard. These tests have been conducted at an R-value of 0.4. Fig. 6 shows a comparison of these data. The open symbols show the ASTM LR test results, while the solid symbols show the CPCA or CPLR test results.

For the ASTM LR tests, the crack was grown from the crack-starter notch to a crack length, which gave a rate of about $10^{-8} \mathrm{~m} /$ cycle and then the LR test was conducted. The results produced a threshold of about $5.75 \mathrm{MPa}-\mathrm{m}^{1 / 2}$. One LR test slightly exceeded the maximum rate requirement, but this test also produced a slightly lower threshold.

For the CP tests, only data that satisfied the crack-extension criterion in shown in the figure. The square symbols show the CPLR test results, which produced a threshold value of about $4 \mathrm{MPa}-\mathrm{m}^{1 / 2}$. Also, the load-reduction test produced lower rates over a significant portion of the $\Delta K$-rate curve. These results illustrate that the ASTM test procedure needs to be modified, in order to remove the load-history effects from the test data. The larger variations in the CP data were due to using the secant method to reduce data, instead of the seven-point polynomial (smoothing) method. The secant method is more sensitive to metallurgical features than the polynomial smoothing method. 
The $\beta$-STOA alloy has a very large grain structure, which caused very rough crack surfaces with meandering and bifurcating cracks.

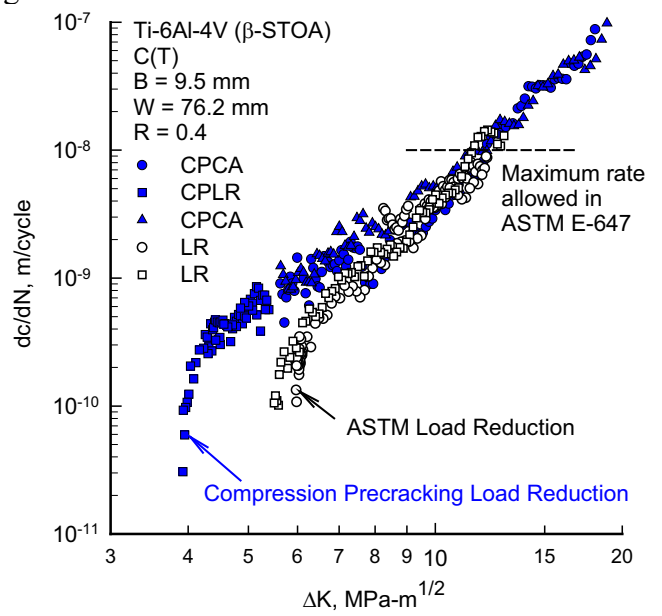

Fig. 6 - Crack-growth rate data on Ti-6Al-4V $\beta$-STOA titanium alloy at $\mathrm{R}=0.4$.

Steel 4340. The measured $\Delta \mathrm{K}$ against rate behavior in the threshold and near-threshold regimes for 4340 steel is shown in Fig. 7 for $\mathrm{R}=0.1$ loading. These data have been generated using the ASTM load-reduction test method (open square, triangle and circular symbols) and the CPCA or CPLR test methods (solid symbols).

To conduct ASTM load-reduction tests, a crack had to be initiated at the V-notch, in such a manner, that the crack-growth rate is equal to or less than $10^{-8} \mathrm{~m} /$ cycles. Constant-amplitude loading $\left(\Delta \mathrm{K}=10 \mathrm{MPa}-\mathrm{m}^{1 / 2}\right)$ was selected to match these conditions, but the cracks would not initiate. Thus, higher loads had to be determined by trial-and-error to produce cracks. Three examples are shown in the figure that required 12 to $16 \mathrm{MPa}-\mathrm{m}^{1 / 2}$ to initiate and grow cracks at the V-notch. At a given constant-amplitude loading, the cracks began to grow away from the V-notch, but once the $\Delta K$ values merged with the baseline curve, the data sharply turned and agreed with the baseline results. The length of the affected zone was about 1.3-mm. Crack growth beyond the affected zone produced the same results as constant-amplitude (notch unaffected) data.

Several possible reasons for this behavior could be the $45^{\circ} \mathrm{V}$-notch influence on the stressintensity factor solution, residual stresses and/or heat-affected material from the electricaldischarge-machined (EDM) notch. Elastic stress analyses of a crack emanating from the V-notch [17] ruled out the stress-intensity factor solution. The affected zone was also too large for a recast zone from EDM notching. Thus, it is suspected that the notch-machining process produced a compressive residual stress field around the V-notch.

Both CPCA and CPLR tests were conducted on the 4340 steel C(T) specimens. Specimens were subjected to a $-800 \mathrm{kN}$ of cyclic compressive load $(\mathrm{R}=36)$ until the crack had grown about $1-\mathrm{mm}$. Compressive yielding at the notch tip and crack growth appears to have wiped out the affected-zone behavior. The specimens were then subjected to constant-amplitude loading ( $45 \mathrm{kN} ; \mathrm{R}=0.1)$ until the crack had grown to the crack-growth criterion and then either a LR or CA test was conducted. The square symbols show the CPCA test results, which show the classic check-mark behavior with high crack-growth rates, a rapid drop, the attainment of a minimum rate, and then an increase in rates, as shown in Fig. 1. The solid circular and triangular symbols show the CPLR test results, which reached a slightly lower threshold than the ASTM LR method. 


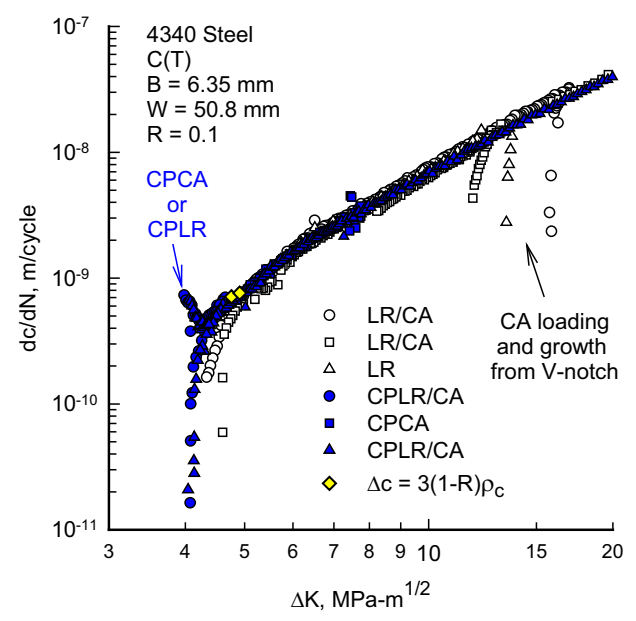

Fig. 7 - Crack-growth rate data on 4340 steel at $\mathrm{R}=0.1$.

Inconel-718. Several ASTM LR and compression precracking tests have been conducted on the Inconel-718 alloy. These data are shown in Fig. 8. The open symbols are the LR test data obtained from Garr, Boeing-Rocketdyne, [23] on $\mathrm{C}(\mathrm{T})$ specimens at $\mathrm{R}=0.1$ and 0.7 .

The solid circular symbols show the results of two CPCA tests at $\mathrm{R}=0.1$. These tests required 20 to 30 million cycles to generate these data. Between $\Delta \mathrm{K}$ values of 8 to $13 \mathrm{MPa}-\mathrm{m}^{1 / 2}$, the crack surfaces developed a dark region, which appears to be fretting debris. At higher rates, the crack surfaces were cleaner and the rates rapidly rose and approached the LR results at about $20 \mathrm{MPa}-$ $\mathrm{m}^{1 / 2}$. The CPCA test results at the lower $\Delta \mathrm{K}$ values were quite different than the LR results, which produce a $\Delta \mathrm{K}_{\mathrm{th}}$ threshold of about $11 \mathrm{MPa}-\mathrm{m}^{1 / 2}$, while the CPCA test was still growing above the threshold rate at $\Delta \mathrm{K}=8 \mathrm{MPa}-\mathrm{m}^{1 / 2}$. The CPCA results also formed a more distinctive lower plateau than the LR test.

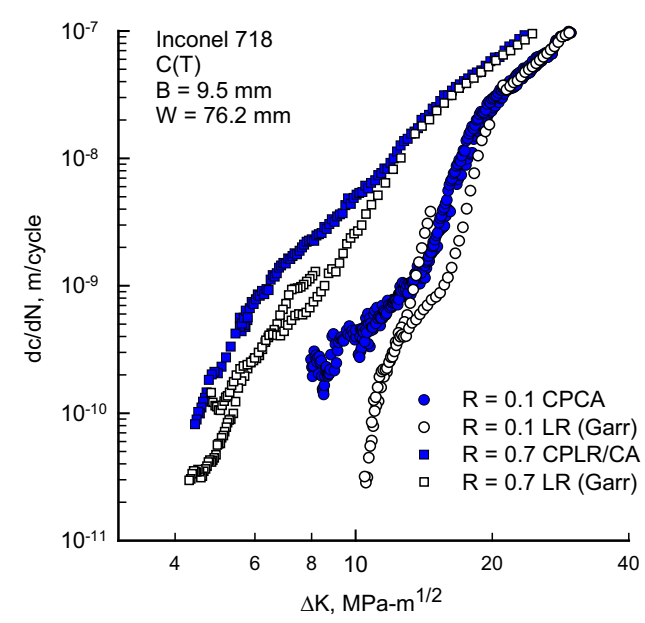

Fig. 8 - Crack-growth rate data on Inconel-718 at $\mathrm{R}=0.1$ and 0.7 . 
A CPLR test was also conducted at $\mathrm{R}=0.7$ (solid square symbols). Surprisingly, the high $\mathrm{R}$ test produced a lower threshold and faster rates than the LR test. Generally, the $\mathrm{R}=0.7$ results on a variety of materials have agreed well between the ASTM LR and CPCA/CPLR tests. However, for the Inconel alloy, a load-history effect from high-R closure may still be causing the differences during the load-reduction test.

\section{Summary}

Some of the fatigue-crack-growth-rate data generated in the threshold and near-threshold regimes on two aluminum alloys (7075-T651, 7075-T7351), a titanium alloy (Ti-6Al-4V $\beta$-STOA), a highstrength 4340 steel and a nickel-based superalloy (Inconel-718) were determined by using the compression precracking constant-amplitude (CPCA) and compression precracking load-reduction (CPLR) test methods. Tests were conducted over a range in stress ratios $(\mathrm{R}=0.1,0.4$ and 0.7$)$ on compact specimens. Results are compared with threshold and near-threshold data generated on the same materials using the ASTM E-647 load-reduction test procedures. The 7075-T651 alloy and 4340 steel showed very little difference between the methods; however, the other materials (7075T7351, Ti-6Al-4V $\beta$-STOA, Inconel-718) showed significant differences with the compression precracking test methods giving lower thresholds and faster crack-growth rates than the ASTM load-reduction method. The Inconel (nickel-based superalloy) even showed significant differences at high R, suggesting that high-R closure may be activated during the load-reduction test.

\section{References}

[1] ASTM International ASTM E-647 Vol. 03.01 (2006).

[2] P.C. Paris, R. Bucci, E. Wessel, W. Clark and T. Mager: ASTM STP 513 (1972), pp. 141-176.

[3] R.A. Schmidt and P.C. Paris, in: Progress in Fatigue Crack Growth and Fracture Testing, ASTM STP 536 (1973), pp. 79-94.

[4] S.J. Hudak, Jr., A. Saxena, R.J. Bucci and R.C. Malcolm: AFML TR 78-40 (1978).

[5] A. Ohta, M. Kosuge and E. Sasaki: Int. J. Fracture, Vol. 14, No. 3 (1978), pp. 251-264.

[6] K. Minakawa and A.J. McEvily: Scripta Metallurgica Vol. 15 (1981), pp. 633-636.

[7] J.C. Newman, Jr. in: AGARD CP-328 (1983), pp. 6.1-6.26.

[8] J.C. Newman, Jr. in: ASTM STP 1372 (2000), pp. 227-251.

[9] S. Suresh, G.F. Zaminski and R.O. Ritchie: Metall. Trans. Vol. A12A (1981), pp. 1435-1443.

[10] R.O. Ritchie: Mater. Sci. Engng. Vol. 103 (1988), pp. 15-28.

[11] B.R. Kirby and C.J. Beevers: Fatigue Fract. Engng. Mater. Struct. Vol. 1 (1979), pp. 203-216.

[12] R.P. Hubbard: J. Basic Eng. Vol. 91 (1969), pp. 625-631.

[13] T.H. Topper and P. Au, in: AGARD Lecture Series 118, Univ. of Denmark, Denmark, (1981).

[14] R. Pippan: Fatigue Fract. Engng. Mater. Struct. Vol. 9 (1987), pp. 319-328.

[15] R. Pippan, L. Plöchl, F. Klanner and H. Stüwe: ASTM J. Testing Eval. Vol. 22 (1994), p. 98.

[16] S.C. Forth, J.C. Newman, Jr. and R.G. Forman: Int. J. Fatigue, Vol. 25 (2003), pp. 9-15.

[17] J.C. Newman, Jr., J. Schneider, A. Daniel and D. McKnight: Int. J. Fatigue, Vol. 27 (2005), pp. 1432-1440. 
[18] Y. Yamada, J.C. Newman, III and J.C. Newman, Jr. in: ASTM Fatigue and Fracture Mechanics $36^{\text {th }}$ Symposium, Tampa, FL (2007).

[19] J.K. Donald and P. Paris, in: Fatigue Damage Structural Materials II, Cape Cod, MA, (1998).

[20] J.C. Newman, Jr. NASA TM 104159 (1992).

[21] J. Ruschau and J.C. Newman, Jr. in: ASTM Fatigue \& Fracture Mechanics: $36^{\text {th }}$ Symposium, Tampa, FL (2007).

[22] R.G. Forman: NASA Johnson Space Center, private communication (2003).

[23] K.R. Garr: Boeing-Rocketdyne Propulsion and Power Company, private communication (2004). 